\title{
Mere Exposure as a Signal: Company Objectives and Research Propositions
}

\section{Kristin A. Scott \& Margaret A. White}

To cite this article: Kristin A. Scott \& Margaret A. White (2016) Mere Exposure as a Signal:

Company Objectives and Research Propositions, Journal of Marketing Theory and Practice, 24:4, 411-421, DOI: 10.1080/10696679.2016.1205448

To link to this article: https://doi.org/10.1080/10696679.2016.1205448

册 Published online: 02 Sep 2016.

Submit your article to this journal $\pi$

Џlll Article views: 124

View Crossmark data $\nearrow$

4 Citing articles: 3 View citing articles 


\title{
MERE EXPOSURE AS A SIGNAL: COMPANY OBJECTIVES AND RESEARCH PROPOSITIONS
}

\author{
Kristin A. Scott and Margaret A. White
}

\begin{abstract}
As companies spend more and more money on product placement, what do they hope to gain from it? The current research answers this question by combing two divergent literature streams: mere exposure and signaling theory and proposing that this type of contact with the product is an example of mere exposure used as a signal by companies in presenting themselves to the consumer. To develop this theoretical framework, eighteen research propositions are proposed. Combining these two divergent literature streams provides a new perspective on how companies can communicate with consumers: companies may send a signal to consumers using mere exposure.
\end{abstract}

As you watch a favorite comedy series like Seinfeld, Jerry walks out of the kitchen eating from a box of Cheerios as he talks to Kramer. In Austin Powers, the characters sit around a table for a meeting with a Starbucks cup sitting on the table. Tom Hanks asks for a Dr. Pepper on the airplane on his return home in the movie Castaway. Ever since E.T. made Reese's Pieces fly in $E$. $T$., movies, TV shows, video games, and music videos have used product placement as a way to advertise to consumers in a non-obtrusive manner. Now, this type of advertising is a billion- dollar industry. Paid global product placement spending is expected to grow at a compounded annual rate of 20 percent over 2005-2012 to $\$ 8.25$ billion (Quinn and Ames 2013).

Because of this increase in product placement by companies, research has begun to investigate the how and why of product placement. An overarching framework of these studies suggest that execution factors (e.g., placement modality) and individual-difference factors (e.g., skepticism toward advertising) affect the processing type (e.g., implicit v. explicit memory) which influence effects from placement (e.g., placement recall) (Balasubramanian, Karrh, and Patwardhan 2006). Specifically, studies show that prominent placements obtain higher recall than do advertisements and subtle placements (Gupta and Lord 1998) and product

Kristin A. Scott (Ph.D., Oklahoma State University), Associate Professor, Marketing and International Business, Minnesota State University, Mankato, Mankato, MN 56001, kristin.scott@mnsu.edu.

Margaret A. White (Ph.D., Texas A\&M University), Fleming Companies, Inc. Professor in Technology Management, Department of Management, Oklahoma State University, Tulsa, Tulsa, OK 74106, margaret.white@okstate.edu. placement enhances product recall, recognition, and choice (Law and Braun 2000). Brands presented only visually are least recalled but most influential on choice, while audiovisual placements are best remembered but least chosen (Law and Braun 2000). Product placement with children demonstrates that age, which implies processing functions, is not a factor in affecting choice since implicit memory is more important than explicit recall (Auty and Lewis 2004). Thus, choice is not correlated with recognition or recall measures, showing that the two are gauging different perceptions (Law and Braun 2000). While this research sheds light on the mechanics of product placement, it does not examine product placement from the company's perspective. As companies spend more and more money on product placement, what do they hope to gain from it?

The current research attempts to answer this question by combining two divergent literature streams: mere exposure and signaling theory and proposing that this type of contact with the product is an example of mere exposure used by companies to signal presence to the consumer. Mere exposure is the act of bringing a stimulus into perception and after being exposed to a new stimulus, a person's liking for that stimulus increases. Spence (2002) defined signaling theory as addressing the amount of information asymmetry between sender and receiver and the signaling process is designed to increase information sharing, develop familiarity, and promote connection. As such, the product (or focus of the signal) will gain in awareness level (Kwan, Yap and Chiu 2015; Zhu and Chang 2015). This contact could subsequently enhance the consumer's attitude toward the product (i.e., the mere exposure effect). Therefore, when a consumer has been exposed 
to a product, logo, or company name, their liking toward it should increase. This stimulus will usually be presented in a non-informational, non-advertising context to reduce cognitive responses and potential responsive barriers. This type of signal occurs in product placement along with other types of mere exposure (e.g., billboards, t-shirts, and banner advertising).

This research suggests that there are two broad company objectives associated with using mere exposure as a signal: bringing the stimulus into perceptual exposure and enhancement of attitude. These objectives are based on the fundamental principle of mere exposure: that bringing a stimulus into perceptual exposure increases the attitude toward the stimulus. The specific objectives associated with perception are awareness (recognition and recall), accessibility, reminder, and association. Familiarity, credibility, quality, reputation, and popularity are the objectives associated with enhancement of attitude. Thus, a firm would benefit from making their product accessible to the consumer to gain an enhancement of attitude, which will result in favorable feelings toward the product and/or company. This positive feeling should finally lead to the ultimate goal of increased buying potential for the product. Recognizing and empirically testing this concept will provide greater insight to both the mere exposure and signaling literature as well as provide managers useful guidelines when utilizing this method. The proposed framework is diagrammed in Figure 1.
Although there has been substantial research in both the signaling and mere exposure literature, mere exposure has not been identified as a type of signal that can reduce asymmetry and increase familiarity and connection with the product/service. This article makes this connection and provides a context from the company's perspective. In addition, it provides a conceptual framework of the objectives of this relationship on which propositions are derived and can be empirically tested. The current article explains and defends this position in the following manner. First, a literature review of both mere exposure and signaling theory is presented. Second, from this literature, the rationale for a signal of familiarity is presented along with the objectives from which propositions regarding mere exposure as a signal can be drawn. Finally, marketing and societal implications of mere exposure as product placement are examined.

\section{LITERATURE REVIEW}

\section{Signaling Theory}

The underlying premise of signaling theory involves information economics in which buyers and sellers possess asymmetric information when involved in a market interaction. In neoclassical economics, it is assumed that buyers and sellers in the marketplace are equally informed about the quality of goods and

Figure 1

\section{Company Objectives for a Mere Exposure Signal}

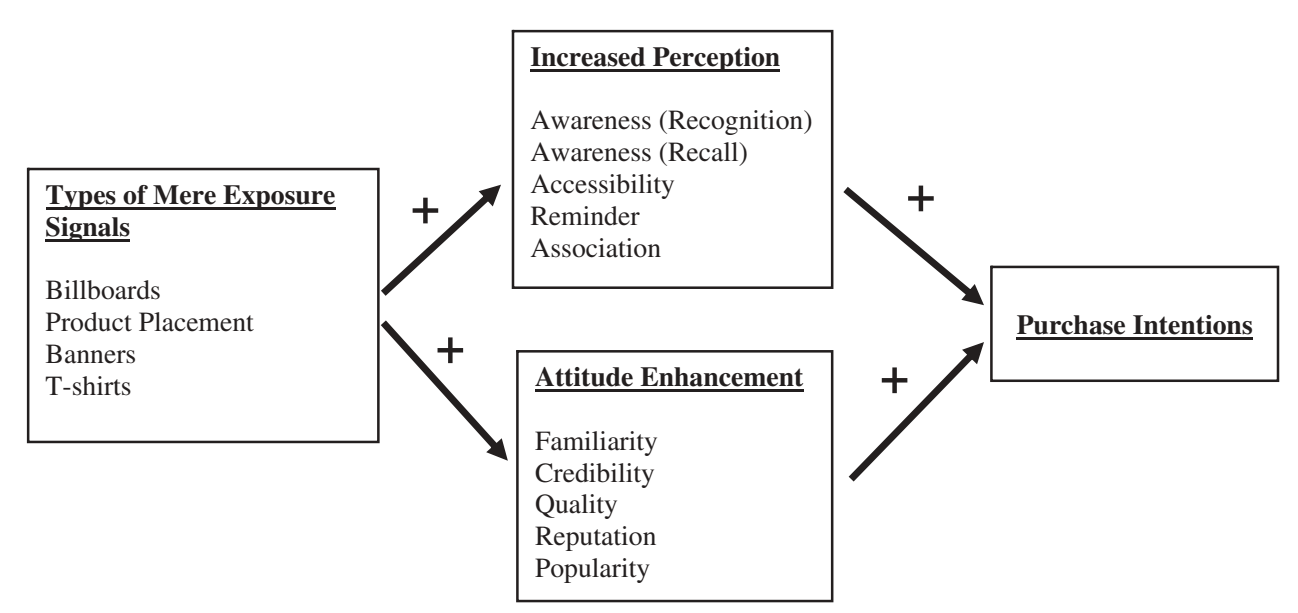


services. However, this assumption is rarely met (Akerlof 1970; Stigler 1961). Because firms have better knowledge about the quality of the products they sell than consumers and consumers cannot readily evaluate the product quality of experience, a need arises for market mechanisms by which firms can credibly inform consumers about the quality of their products (Erdem and Swait 1998). These mechanisms are known as "signals" and are one solution by marketers to reduce the problem of information asymmetry (Akerlof 1970). Consumers can look for certain signals to determine quality that would be beneficial for a high quality seller to send, but unbeneficial for a low quality seller. For sellers with different levels of quality, the signal is differentially costly to produce (Rao and Ruekert 1994). However, in markets where sellers find it profitable to cheat, and where there are no incentives for low-and high-quality sellers to choose different strategies, buyers are unable to differentiate by signals (Erdem and Swait 1998). Many different types of signals have been identified including advertising (e.g., Nelson 1974), umbrella branding (e.g., Wernerfelt 1988), retailer reputation (e.g., Chu and Chu 1994), and brand equity (e.g., Erdem and Swait 1998). The advertising signaling literature includes such topics as advertising repetition (Kirmani 1997), advertising and quality (Nelson 1974), and perceived advertising cost (Kirmani and Wright 1989).

\section{Mere Exposure}

Mere exposure is a "condition which makes the specific stimulus accessible to the individual's perception" (Zajonc 1968, p. 1) and seminal research shows that repeated mere exposure increases liking for a stimuli (Zajonc 1968). Later research demonstrates that recognition of the stimulus is not a prerequisite for subsequent attitudes. This subliminal mere exposure effect occurs even though subjects cannot discriminate exposed stimuli from novel stimuli in a recognition memory test (Kunst-Wilson and Zajonc 1980) and subliminal stimuli are actually more effective in producing mere exposure results than in instances where subjects could recognize the stimulus (Bornstein 1989; Bornstein and D'Agostino 1992). Additional research has shown that antecedents of preferences may involve both cognitive and affective components but preferences are primarily affectively based behavioral phenomena (italics in original) (Zajonc and Markus 1982). Thus, attempting to change an attitude that has evolved from affective sources may require different methods than to change an attitude based on cognition: attitudes that have an emotional basis can only be changed by methods that have a direct emotional influence (Zajonc and Markus 1982). Beyond attitudes, mere exposure has also been shown to increase approach behaviors such that participants select an approach response more frequently for familiar compared to novel stimuli (Jones, Young, and Claypool 2011).

The mere exposure effect has also been extended into an advertising context. Research indicates that incidental exposure to advertisements can increase liking for an advertisement, brand name, and product packages included in the advertisement (Janiszewski 1993) and that brand names should be put continuously throughout the advertisement to increase effectiveness and a high priority should be placed on maximizing the importance of the brand name and package in advertisements (Baker 1999). Complexity of the design is also important since preferences of complex designs improved with repeated exposure, preferences for simple designs decreased, and moderately complex designs were preferred most, forming an inverted U (Cox and Cox 2002). The relationship between advertising repetition and affective ratings depend on the level of processing with deeper processing causing an inverted U-shape while shallow processing results in an increasing pattern that does not decrease (Nordhielm 2002).

\section{THEOTREICAL DEVELOPMENT: MERE EXPSOURE AS A SIGNAL}

Linking these two literature streams provides a new perspective on how companies can communicate with consumers: companies may send a signal to consumers using mere exposure. In their review of signaling theory, Connelly et al. (2011) indicated general signal effectiveness is characterized by frequency, observability, clarity, quality, fit, and consistency. Effective mere exposure activities have the same characteristics. The firm as signaler wants to establish a method of providing the receiver a frequent perception without intrusion, an unobtrusive observation, an impression of fit between the firm and consumer while providing a consistent signal (message). The results of such efforts are connection, familiarity, and hopefully purchase. Mere exposure (a non-advertising context) can provide valuable information and association 
to consumers which can increase purchase intentions. The signal used by the company may be in the form of a brand ("a name, term, sign, symbol, or design, or combination of them which is intended to identify the goods and services of one seller or group of sellers and to differentiate them from those of competitors" (Kotler 1997, p. 136), logo, or company name. These signals could be used in a number of different contexts including billboards, product placement, t-shirts, and web banners.

There are three benefits for the company utilizing mere exposure as a signal. First, having the product presented to the consumer in a non-advertising, non-intrusive context should reduce possible negative cognitive responses that advertising can induce. Second, using mere exposure may be less expensive than traditional advertising. Third, consumers may be unaware that they are being exposed to the product so negative effects may be misattributed to other factors (e.g., seeing or hearing about the product through a commercial).

To develop this theoretical framework, eighteen research propositions categorized into three sections are proposed. The first section describes and classifies mere exposure as a signal. The second and third sections provide company objectives that can be broadly categorized as either gaining perception or enhancing attitude. Gaining perception can be further categorized as awareness (recognition and recall), accessibility, reminder, or association objectives. When attempting to enhance attitudes, companies may use familiarity, credibility, quality, reputation, or popularity as an objective.

\section{Classifying Mere Exposure as a Signal}

Different types of signals may be classified based on the monetary consequence incurred by the firm (Kirmani and Rao 2000). Default-independent signals occur when the monetary loss occurs independently of whether the firm defaults on its claim while defaultcontingent signals occur when the monetary loss occurs only when the firm defaults on its claim (see Table 1). For example, investments in advertising are incurred regardless of whether the firm's claim is true or false while a manufacturer's warranty does not involve up-front expenditures and will only be monetarily detrimental if a firm defaults on their claim (Kirmani and Rao 2000). These two categories are each further divided on the basis of the nature of the bond at stake. Default-independent signals differ as to whether the expenditure depends on an actual sale: sale-independent signals involve expenditures that occur whether or not a sale occurs (e.g., advertising) while sale-contingent signals involve expenditures only in the presence of a sales transaction (e.g., low introductory price). The further classification of default-contingent signals is based on the potential of future consequences should the firm's quality claim turn out to be false. Under this category, revenue-risking signals are signals that offer the firm's future revenues as a hostage while cost-risking signals offer the firm's costs as a hostage.

Using this typology, mere exposure as a signal would fall under sale-independent signals. Here, the monetary loss of the firm is incurred independently of whether the firm defaults on its claim and whether or not a sale occurs. Thus, firms must pay for the cost of the product placement up-front whether or not a sale takes place and this cost to the company is incurred even if the claim made is not true. The characteristics of this category include expenditures that are publicly visible before sale, monetary loss that is fixed, repeat purchase is important, direct utility is not received by the buyer, and there is no potential for abuse by consumers (Kirmani and Rao 2000). This type of signal is appropriate when the buyer

Table 1

Types of Signals (adapted from Kirmani and Rao 2000)

\begin{tabular}{|c|c|c|c|c|}
\hline & \multicolumn{2}{|c|}{ Default-Independent Signals } & \multicolumn{2}{|c|}{ Default-Dependent Signals } \\
\hline & Sale-Independent & Sale-Contingent & Revenue-Risking & Cost-Risking \\
\hline Examples & Advertising, mere exposure & Low introductory price, coupons & $\begin{array}{l}\text { High price, brand } \\
\text { vulnerability }\end{array}$ & $\begin{array}{l}\text { Warranties, money-back } \\
\text { guarantees }\end{array}$ \\
\hline Characteristic & $\begin{array}{l}\text { Publicly visible expenditures } \\
\text { before sale }\end{array}$ & $\begin{array}{l}\text { Private expenditures during sales } \\
\text { transaction }\end{array}$ & Future revenues at risk & Future costs at risk \\
\hline $\begin{array}{l}\text { Appropriate } \\
\text { when }\end{array}$ & $\begin{array}{l}\text { Buyer cannot be easily } \\
\text { identified }\end{array}$ & Buyer can be easily identified & $\begin{array}{l}\text { Frequently purchased } \\
\text { nondurables }\end{array}$ & Durables \\
\hline
\end{tabular}


cannot be identified easily (Kirmani and Rao 2000). From these characteristics, two propositions can be made regarding mere exposure as a signal:

$\mathrm{P}_{1}$ : Consumers will attribute the cost of using mere exposure signals as an upfront expenditure by the company.

$\mathrm{P}_{2}$ : Companies will use mere exposure signals more often when the buyer base is large and it is difficult to identify customers.

\section{Search Qualities/Durable Products}

Goods and services may have two different types of qualities: search qualities where quality is attained prior to purchase and experience qualities in which quality is attained only after purchase (Nelson 1974). Consequently, advertising for experience qualities is mostly indirect information while advertising for search qualities is mostly direct information. The primary information content of advertisements for experience goods is that the brand advertises, which results in information being predominantly indirect (Nelson 1974). In the case of search goods, direct information will have a greater value to the consumer than indirect information. Since mere exposure uses no direct information but simply exposes the consumer to the product, it is predicted that experience goods will use mere exposure more than will search goods. With both experience and search qualities, advertising is greater for nondurables than for durables (Nelson 1974). This relationship is also predicted to hold for mere exposure signals.

$\mathrm{P}_{3}$ : Companies will use mere exposure signals more frequently for experience products than for search products.

$\mathrm{P}_{4}$ : Companies will use mere exposure signals more frequently for nondurable products than for durable products.

\section{Company Objective: Increase Perception}

When mere exposure was first introduced, it was defined as a "condition which makes the specific stimulus accessible to the individual's perceptions" (Zajonc 1968, p. 1). A broad objective for firms when using mere exposure as a signal is simply putting the product/company name/logo in front of the consumer (frequency and observability). The particular objectives of perception include awareness using recognition and recall, accessibility, reminder, and association.

\section{Awareness (Recognition)}

Companies may desire to gain awareness of their product or company with their target audience, especially when a new brand is introduced or a new company has been established. Mere exposure provides a venue for companies to display the product, name, or logo in an unobtrusive manner that will provide awareness for the target audience. Recognition is an important objective for companies and a consequence of mere exposure. A brand that is more easily recognized than competition may benefit from increased purchase intention. Here, the importance is only that a person can recognize the brand but may not necessarily be able to recall it; for example, being able to recognize a certain brand upon seeing it at the store. Recognition is also an important component in measuring the effectiveness of product placement.

$\mathrm{P}_{5}$ : Mere exposure signals will increase recognition of a product/company.

\section{Awareness (Recall)}

Here, the company desires that the consumer can recall the stimulus which is a deeper awareness than simply recognizing the stimulus. Thus, consumers are able to recall the name of the product/company from memory unaided. Since this is a deeper awareness than simply recognizing a product/company, companies would especially benefit from top of the mind awareness or being an exemplar of a category. Companies may be able to achieve this objective by using a mere exposure signal since this creates an environment where the brand/company is ubiquitous and the more that it is seen increases the chances of being able to be recalled unaided. For example, when thinking about what laundry detergent to purchase at the store, the consumer recalls this information from memory. Findings from the product placement literature suggest that companies should consider differences between visual and audio placements since audiovisual placements are best remembered (but least chosen) (Law and Braun 2000). 
$\mathrm{P}_{6}$ : Mere exposure signals will increase recall of a product/company.

\section{Accessibility}

Accessibility can be defined as the activation potential of available knowledge (Higgins 1996). Companies may want to increase the accessibility of their products to increase the likelihood that they are considered for purchase. One way to increase the ease with which a name can be brought to mind is to have prior exposure to it (Higgins 1996). The more accessible a brand attitude, the more likely a consumer will access the attitude upon observing cues associated with the brand (Fazio 1986). Therefore, a company and/or product name shown to consumers often should increase the chance that they will remember it and access the attitude attributed to the product. If a product is more accessible, it should be more likely to be recalled later.

$\mathrm{P}_{7}$ : Mere exposure signals will increase accessibility of a product/company.

\section{Reminder}

Companies may use reminder ads to prompt consumer's memory of that brand and keep the brand name in front of consumers (consistency and frequency). Especially in cases of well-established brands, companies need to remind the consumer that the product is present and should be considered. Using mere exposure to send a reminder to the target audience should remind consumers of the product and increase purchase intentions. The product placement literature suggests that it is previous exposure along with a reminder in the form of product placement that affects choice (Auty and Lewis 2004).

$\mathrm{P}_{8}$ : Mere exposure signals will serve as a reminder of the product/company.

\section{Association}

In some instances, companies may desire to have certain attributes associated with their product to enhance connectedness and observability. As suggested by the meaning transfer model, having a well-known actor wear a pair of jeans may make the jeans take on the characteristics of the actor and consumers may then purchase the product to receive the endowed characteristics (McCracken 1989). Combining a brand with a character would focus more attention to the brand and would also prompt more thinking about the combination (Karrh, McKee, and Pardun 2003). In theory, frequent activation of a specific "attitude object-evaluation" linkage can increase the consistency between people's attitude toward an object and their behavioral response to that object (Fazio et al. 1982). This finding suggests that if a product is paired with a certain evaluation such as sexy, then frequent repetitiveness of this association could lead to behavioral responses to the object. Using mere exposure to associate a brand with certain qualities should make the brand take on these characteristics. Repeated exposure may then lead to behavioral outcomes (Jones et al. 2011).

$\mathrm{P}_{9}$ : Using mere exposure signals, products that are associated with certain qualities will take on the suggested attributes.

$\mathrm{P}_{10}$ : Frequent activation of these suggested attributes will lead to behavioral responses.

\section{Company Objective: Enhancement of Attitudes}

The mere exposure effect suggests that once the stimulus has been brought into perception that increased exposure will enhance the attitudinal response toward it. Original studies suggest that increased repetition will increase attitudes toward the product (Zajonc 1968). However, this relationship depends on the processing of the stimuli so that when shallow processing takes place, a monotonically increasing relationship is proposed to exist while deeper processing forms an inverted U (Nordhielm 2002). In the case of mere exposure as a signal, the consumer is not required to engage in extensive cognitive processing since there is no direct information. Therefore, it is suggested that a linear relationship will exist between frequency and subsequent liking (fit). However, this relationship will not hold if a prominent product placement is used (Homer 2009). 
$\mathrm{P}_{11}$ : Using mere exposure signals, as the frequency of the stimulus increases, positive affective responses will increase in a monotonic relationship.

Besides repetition and prominence, duration may influence the attitudinal relationship. Bornstein's (1989) meta-analysis suggests that the longer the stimulus is shown, the less it will be liked in subsequent ratings. In a product placement context, products can be shown for a range of duration time. If liking increases with shorter duration time, then firms would be advised to show their product for a short amount of time, decreasing the cost associated with the product placement. Thus, it is proposed that:

$\mathrm{P}_{12}$ : Using mere exposure signals, as the duration time of a product increases, positive affective responses will decrease.

Enhancement of attitudes as an objective can be further divided into more detailed objectives, which include: familiarity, credibility, quality, and reputation. All of these are closely related to the characteristics of effective signals (c.f., Connelly et al. 2011).

\section{Familiarity}

Increasing familiarity of a brand with the target audience is advantageous to companies for several reasons. First, a brand that is familiar will be preferred, since familiarity signals that it is tried-and-trusted (Holden and Vanhuele 1999). Second, for familiar brands, the degree of liking is well-established and stable because brand-related experiences and associations are extensive (Bettman and Sujan 1987) but for unfamiliar brands, preexisting attitudes may be unformed or weak in terms of attitude strength and accessibility (Fazio 1986). Third, because of the extensiveness of associations and strength of affect that a familiar brand already holds, attitudes toward a familiar brand will be more resistant to change (Simonin and Ruth 1998) and choice times are faster when one brand is more familiar (Ambler et al. 2004). In addition, consumer decisions can be influenced by a sense of familiarity even without the recollection of where it came from (Law and Braun 2000). Because of these benefits of familiarity, it would be beneficial to a company to make their product more familiar compared to the competition. One way of accomplishing this would be to use mere exposure; because after many exposures, the brand should seem more familiar and consumers might not be able to attribute the source of familiarity.

$\mathrm{P}_{13}$ : Mere exposure signals will increase the familiarity of a product/company.

\section{Credibility}

Erdem and Swait (1998) suggest that brands themselves are seen as information sources for consumers and credibility is the key element in the signaling perspective on brand equity. The content, clarity, and credibility of a brand as a signal of the product's position may increase perceived quality and decrease information costs and perceived risk for consumers. They suggest that if consumers are uncertain about product attributes, firms may use a brand to signal that their product claims are credible. These brand names have utility because they are sources of information that identify the manufacturer (Rao and Ruekert 1994). If the company defaults on the claim, the consumer knows who can be held responsible. This signaling perspective may make brand names more effective as signals of product positions than individual mix elements such as advertising, price, or warranty (Erdem and Swait 1998). Because mere exposure is one way to display the brand to consumers, this exposure should increase the credibility of the brand.

$\mathrm{P}_{14}$ : Mere exposure signals will increase the perceived credibility of a product/company.

\section{Quality}

Using mere exposure as a signal could affect perceived quality by exposing the consumer to the name of the brand. An important function of brand names is to give consumers information about product quality (Rao and Ruekert 1994). A brand name can be an effective signal of unobservable quality since they identify who the manufacturer is, who can be punished if the brand does not meet expectations (Rao, Qu, and Ruekert 1999). Brands that are most likely to have repeat purchase have the greatest payoff to improve consumer memory. Therefore, brands that have the highest utility have the greatest incentive to advertise (Nelson 1974). If a high-quality brand is advertised more, then 
rational, informed consumers will respond positively to advertising, even if the ads cannot and do not have much direct informational content (Milgrom and Roberts 1986). In the context of mere exposure as a signal, there is no direct information given to the consumer-only that product or brand name is being presented. This exposure should increase quality perceptions since it is perceived that these products have high utility (value) and would benefit from the exposure. Thus, it is more beneficial for a high-quality brand to incur the up-front expenditure for the product placement than a low-quality brand that will not benefit from repeat purchases if the quality is low.

$\mathrm{P}_{15}$ : Mere exposure signals will increase the perceived quality of the product/company.

However, this relationship may be dependent on the number of times the product is shown in a given time span. Signaling theory proposes that repetition may serve as a cue for consumers as to the quality of an unfamiliar brand. Thus, a consumer may make inferences about the creditability of an unfamiliar manufacturer from the amount of repetition (Kirmani 1997). Research shows that the relationship between advertising repetitions and perceived brand quality is an inverted $U$ for color ads (Kirmani 1997). Thus, showing a product too many times during a given period may decrease quality perceptions.

$\mathrm{P}_{16}$ : Perceived quality of the product/company will be dependent on the repetition for mere exposure signals.

\section{Reputation}

High exposure of a brand may increase the reputation of that brand since it would be expected that only reputable brands with high utility would be promoted. If firms do not deliver the high quality, they will lose return on their brand investments, their reputation, or both (Erdem and Swait 1998). This high exposure can be easily established in a mere exposure context. After hearing a brand name only once, a feeling of familiarity is created and if the exposure context is forgotten, it will give the false impression that the name is for an established, existing brand (Holden and Vanhuele 1999). Thus, a brand might be able to gain a reputation without having to work for it since seeing or hearing a brand name should increase the perception that the brand is reputable. Prior exposure to the brand may also be misattributed to that brand being popular, especially if the brand is seen many times as mere exposure. Thus, if the brand is seen everywhere from TV shows to t-shirts, it would create a perception that the brand was popular even if most of these exposures were company-placed (e.g., giving out free t-shirts) rather than from true popularity among the public. From this research two propositions can be made:

$\mathrm{P}_{17}$ : Mere exposure signals will increase the perceived reputation of a product/company.

$\mathrm{P}_{18}$ : Mere exposure signals will increase the perceived popularity of a product/company.

\section{THEORETICAL IMPLICATIONS}

The current research makes an important theoretical contribution by bridging two literature streamsmere exposure and signaling theory - to explain the rationale behind product placement used by companies. Despite significant research in both of these literature streams, research has failed to examine them from a company's perspective which provides important insights about the use and possible outcomes of these strategies. By identifying mere exposure as a type of signal, it provides another avenue in which companies can reduce asymmetry and increase familiarity and connection with the product/service, all of which are important goals for companies. Many types of signals have been identified in the literature- advertising, pricing, warranties, and so on. Adding mere exposure to this list provides additional research opportunities for academics as well as identifies another avenue for which companies can send non-obtrusive information to consumers to reduce information asymmetry. The impact of mere exposure - increased liking - is a huge benefit for companies to take advantage of especially because of the cost benefits as well as the ability to persuade consumers in a way that advertising cannot. The proposed propositions provide a starting point to explore this type of signal which can be empirically validated to give companies concrete recommendations for using this type of signal.

Theoretically, identifying mere exposure as a particular type of signal adds to the signaling literature which has already identified different types of signals. 
Identifying this new signal has important implications because of mere exposure's unique benefits- increased liking. No other signal offers this type of benefit for companies and thus investigating this signal empirically has potential for the field as well as for the benefit of companies. If mere exposure is able to deliver the proposed objectives, it would provide an unobtrusive way to get to the consumer and also offer a cheaper, easier vehicle for obtaining certain results. With the increase in clutter, new technology such as TiVo, Netflix, and HuluPlus, and negative attitudes toward advertising in general, using a method such as mere exposure may become more prevalent. Use of product placement is expected to increase as marketers find more nontraditional vehicles to appeal to timecrunched and marketing-savvy consumers (Law and Braun 2000). Thus, understanding the implications and effects of this signal would prove to be beneficial.

Another consideration is what happens on the receiver end when mere exposure is treated more as a signal than as a non-obtrusive, low information product placement. The set of propositions positioned here have focused on the sender-the firm. In signaling theory, the receiver and the receiver's interpretation of the message being sent influences the utility and outcomes from the signal. Mere exposure is an impactful messaging process-how and what it signals when it is most effective-and should be of interest to marketing professionals and researchers. Signaling theory tells us that if we are able to give effective signals, perceived information asymmetry is reduced and receivers feel more familiar with and connected to the product. Mere exposure when done effectively has the power to do just that.

Boundary conditions would also have to be investigated to find where these results hold (e.g., type of product). One possibility is that mere exposure has the potential to be more effective for types of products that are low-involvement (e.g., soft drinks) as compare to high-involvement products (e.g., computers). Other moderators could include number of exposures as well as placement of exposure. For example, does the exposure matter coming from a movie or TV show as compared to seeing someone wearing a t-shirt? In addition to boundary conditions, there is the possibility that the current propositions could be influenced by each other. For example, as a company attempts to enhance perceived popularity by increasing the repetition of mere exposure $\left(\mathrm{P}_{18}\right)$, the perceived quality of the brand may decrease as a result of the increased repetition $\left(\mathrm{P}_{16}\right)$.
Bud Light is a brand that is very ubiquitous due to mere exposure repetitions and is also perceived to be very popular; however, it is not perceived as a quality beer because of these repetitions.

\section{Future Research}

Conceptualizing mere exposure as a signal requires empirical testing to understand the implications and boundaries of this phenomenon. While a firm may use this a number of ways, the most prevalent method has been product placement. When testing this phenomenon, the type of measurement is important because of the differences in results between implicit and explicit testing. If brand awareness is the objective, then the impact of product placement is best measured with an explicit recall test, which measures recognition and recall. However, if the objective is to increase the chance that a product will be chosen from a consideration set, an implicit measure would best represent the effectiveness, which measures the effect of exposure on product choice indirectly (Law and Braun 2000). In the case of mere exposure, using perception as an objective would be most consistent with an explicit test since the objective is for people to have recognized that they have seen it. Results should produce high recognition and recall of the product. However, attitude enhancement as an objective would be more in line with an implicit memory test. In this case, a consumer is choosing a product because their familiarity toward it has increased but they might not make the cognitive connection that they have seen it before.

Beyond testing the proposed propositions, a possible extension of the product placement literature comes from research in industrial engineering. Research in this area has investigated how much of a sign must be present in order for people to understand the full meaning (e.g., Dutta, Fisher, and Noyce 2004). This context can be extended to the product placement literature. If a product is placed in a movie, how much of it needs to be seen in order for people to know what it is? Placing half a product or half a sign may still be effective in terms of implicit and explicit measures but may cost less to have the product placed. In conjunction, differences in time needed to recognize the product could be measured. If half the product is showing, it may take longer for the consumer to discern what it is. Exploring this area more in depth will 
provide greater insight to managers who decide to implement this tactic.

The continued use of obscure marketing techniques may hold concerns for public policy since it blurs the distinction between advertising and programming (Law and Braun 2000). This may produce ethical concerns since the product placements might not be seen as advertising while producing similar results. This may result in deceitful practices, especially when people do not realize they are being influenced. When viewing advertisements, people realize that the ad is trying to persuade them, leading to cognitive responses. However, in product placement, such cognitive responses are not likely to occur. Because the audience perceives the movie as entertainment and not persuasion, counterarguments are not generated and thus the persuasive impact of the communication may be enhanced (Solomon and Englis 1994). Because of the ethical concerns with this practice, policy makers may wish to establish guidelines for these nontraditional advertising techniques.

\section{REFERENCES}

Akerlof, George A (1970), "The Market for "“Lemons": Quality Uncertainty and the Market Mechanism," Quarterly Journal of Economics, 488-500.

Ambler, Tim, Sven Braeutigam, John Stins, Steven Rose, and Stephen Swithenby (2004), "Salience and Choice: Neural Correlates of Shopping Decisions," Psychology \& Marketing, 21 (4), 247-61.

Auty, Susan and Charlie Lewis (2004), "Exploring Children's Choice: The Reminder Effect of Product Placement," Psychology \& Marketing, 21 (9), 697-713.

Baker, William E. (1999), "When Can Affective Conditioning and Mere Exposure Directly Influence Brand Choice?," Journal of Advertising, 28 (4), 31-46.

Balasubramanian, Siva K, James A Karrh, and Hemant Patwardhan (2006), "Audience Response to Product Placements: An Integrative Framework and Future Research Agenda," Journal of Advertising, 35 (3), 115-41.

Bettman, James R and Mita Sujan (1987), "Effects of Framing on Evaluation of Comparable and Noncomparable Alternatives by Expert and Novice Consumers," Journal of Consumer Research, 14 (2), 141-54.

Bornstein, Robert F (1989), "Exposure and Affect: Overview and Meta-Analysis of Research, 1968-1987," Psychological Bulletin, 106 (2), 265-89.

Bornstein, Robert F and Paul R D'Agostino (1992), "Stimulus Recognition and the Mere Exposure Effect," Journal of Personality and Social Psychology, 63 (4), 545-45.

Chu, Wujin and Woosik Chu (1994), "Signaling Quality by Selling Through a Reputable Retailer: An Example of
Renting the Reputation of Another Agent," Marketing Science, 13 (2), 177-89.

Connelly, Brian L., S. Trevis Certo, R. Duane Ireland, and Christopher R. Reutzel (2011), "Signaling Theory: A Review and Assessment," Journal of Management, 37 (1), 39-67.

Cox, Dena and Anthony D Cox (2002), "Beyond First Impressions: The Effects of Repeated Exposure on Consumer Liking of Visually Complex and Simple Product Designs," Journal of the Academy of Marketing Science, 30 (2), 119-30.

Dutta, Arup, Donald L. Fisher, and David A. Noyce (2004), "Use of a Driving Simulator to Evaluate and Optimize Factors Affecting Understandability of Variable Message Signs," Transportation Research Part F: Traffic Psychology and Behaviour, 7 (4), 209-27.

Erdem, Tülin and Joffre Swait (1998), "Brand Equity as a Signaling Phenomenon," Journal of Consumer Psychology, 7 (2), 131-57.

Fazio, Russell H (1986), "How Do Attitudes Guide Behavior," in Handbook of Motivation and Cognition: Foundations of Social Behavior, Vol. 1, ed. Richard M. Sorrentino and Edward Tory Higgins, New York: Guildord Press, 204-43.

Fazio, Russell H, Jeaw-Mei Chen, Elizabeth C McDonel, and Steven J Sherman (1982), “Attitude Accessibility, Attitude-Behavior Consistency, and the Strength of the Object-Evaluation Association," Journal of Experimental Social Psychology, 18 (4), 339-57.

Gupta, Pola B and Kenneth R Lord (1998), "Product Placement in Movies: The Effect of Prominence and Mode on Audience Recall," Journal of Current Issues \& Research in Advertising, 20 (1), 47-59.

Higgins, Edward Tory (1996), "Knowledge Activation: Accessibility, Applicability, and Salience," in Social Psychology Handbook of Basic Principles, ed. Edward Tory Higgins and Arie W. Kruglanski, New York: Guilford Press, 133-68.

Holden, Stephen J.S. and Marc Vanhuele (1999), "Know the Name, Forget the Exposure: Brand Familiarity Versus Memory of Exposure Context," Psychology and Marketing, 16 (6), 479-96.

Homer, Pamela Miles (2009), "Product Placements: The Impact of Placement Type and Reptition on Attitude," Journal of Advertising, 38 (3), 21-32.

Janiszewski, Chris (1993), "Preattentive Mere Exposure Effects," Journal of Consumer Research, 376-92.

Jones, Isaiah F., Steven G. Young, and Heather M. Claypool (2011), "Approaching the Familiar: On the Ability of Mere Exposure to Direct Approach and Avoidance Behavior," Motivation and Emotion, 35 (4), 383-92.

Karrh, James A, Kathy Brittain McKee, and Carol J Pardun (2003), "Practitioners' Evolving Views on Product Placement Effectiveness," Journal of Advertising Research 43 (2), 138-49.

Kirmani, Amna (1997), "Advertising Repetition as a Signal of Quality: If It's Advertised So Much, Something Must Be Wrong," Journal of Advertising, 26 (3), 77-86.

Kirmani, Amna and Akshay R Rao (2000), "No Pain, No Gain: A Critical Review of the Literature on Signaling 
Unobservable Product Quality," Journal of Marketing, 64 (2), 66-79.

Kirmani, Amna and Peter Wright (1989), “Money Talks: Perceived Advertising Expense and Expected Product Quality," Journal of Consumer Research, 16 (3), 344-53.

Kotler, Philip (1997), Marketing Management, Upper Saddle River, NJ: Prentice Hall.

Kunst-Wilson, William Raft and Robert B. Zajonc (1980), "Affective Discrimination of Stimuli That Cannot Be Recognized," Science, 207 (1), 557-58.

Kwan, Letty Y-Y., Suhui Yap, and Chi-yue Chiu (2015), "Mere exposure affects perceived descriptive norms: Implications for personal preferences and trust," Organizational Behavior and Human Decision Processes, $129,48-58$.

Law, Sharmistha and Kathryn A Braun (2000), "I'll Have What She's Having: Gauging the Impact of Product Placements on Viewers," Psychology \& Marketing, 17 (12), 1059-75.

McCracken, Grant (1989), "Who Is the Celebrity Endorser? Cultural Foundations of the Endorsement Process," Journal of Consumer Research, 16 (3), 310-21.

Milgrom, Paul and John Roberts (1986), "Price and Advertising Signals of Product Quality," The Journal of Political Economy, 94 (4), 796-821.

Nelson, Phillip (1974), "Advertising as Information," Journal of Political Economy, 82 (4), 729-54.

Nordhielm, Christie L (2002), "The Influence of Level of Processing on Advertising Repetition Effects," Journal of Consumer Research, 29 (3), 371-82.

Quinn, Patrick and Tabor Ames (2013), "New Pq Media Data," prweb, Beltsville, MD, April 15, (available at h t t p : / / www.prweb.com/releases / 2013 / 4 / prweb10626564.htm).
Rao, Akshay R, Lu Qu, and Robert W Ruekert (1999), "Signaling Unobservable Product Quality Through a Brand Ally," Journal of Marketing Research, 36 (2), 258-68.

Rao, Akshay R. and Robert W. Ruekert (1994), "Brand Alliances as Signals of Product Quality," MIT Sloan Management Review, 36 (1), 87-97.

Simonin, Bernard L and Julie A Ruth (1998), "Is a Company Known by the Company It Keeps? Assessing the Spillover Effects of Brand Alliances on Consumer Brand Attitudes," Journal of Marketing Research, 35 (1), 30-42.

Solomon, Michael R and Basil G Englis (1994), "Observations: The Big Picture: Product Complementarity and Integrated Communications," Journal of Advertising Research, 34 (1), 57-63.

Spence, Michael (2002), "Signaling in Retrospect and the Informational Structure of Markets," American Economic Review, 92 (3), 434-59.

Stigler, George J (1961), "The Economics of Information," Journal of Political Economy, 69 (3), 213-25.

Wernerfelt, Birger (1988), "Umbrella Branding as a Signal of New Product Quality: An Example of Signalling by Posting a Bond," RAND Journal of Economics, 19 (3), 458-66.

Zajonc, Robert B (1968), "Attitudinal Effects of Mere Exposure," Journal of Personality and Social Psychology Monograph Supplement, 9 (2), 1-27.

Zajonc, Robert B and Hazel Markus (1982), "Affective and Cognitive Factors in Preferences," Journal of Consumer Research, 9 (2), 123-31.

Zhu, Dong Hong, and Ya Ping Chang (2015), "Effects of interactions and product information on initial purchase intention in product placement in social games: the moderating role of product familiarity," Journal of Electronic Commerce Research, 16 (1), 22. 